approximate the two-electron integrals and all core orbitals are excluded from the treatments. According to prior experience, the estimated error for the relative energies due to the $\mathrm{RI}$ approximation is less than $0.05 \mathrm{eV} \cdot{ }^{[7]}$ The valence $A O$ basis sets are taken from ref. [4]. The exponents of the $d$ - and f-functions are taken from the correlation-consistent basis sets of Dunning. ${ }^{[12]}$ The MP2-optimised auxiliary basis sets used in the RI approximation are taken from the TURBOMOLE library. ${ }^{[13]}$

The MR-MP2 calculations are performed as described in detail in ref. [7]. As a MO basis, HF orbitals are used. The reference functions are made from all single and double excitations within an active orbitals space of (20/20, ring), (18/19, bowl) and (18/18, cage). These active spaces were chosen such that the largest amplitude in the first-order MP2 corrected wave function does not exceed 0.03 . The configuration selection threshold was set to $0.1 \mu E_{\mathrm{h}}$ so that about $80 \%$ of the MR-MP2 correlation energy is obtained exactly and only $20 \%$ is taken in the diagonal approximation (for details see ref. [7]). The MR-MP2 calculations have been performed in parallel on a Linux PC cluster by the RIMR $^{[14]}$ program developed in our laboratory.

[1] H. Prinzbach, A. Weiler, P. Landenberer, F. Wahl, J. Wörth, L. T. Scott, M. Gelmont, D. Olevano, B. von Issendorff, Nature 2000, 407, 60.

[2] S. Sokolova, A. Lüchow, J. B. Anderson, Chem. Phys. Lett. 2000, 323, 229

[3] K. Ragavachari, D. L. Stout, G. K. Odom, G. E. Scuseria, J. A. Pople, B. G. Johnson, P. M. W. Gill, Chem. Phys. Lett. 1993, 214, 357.

[4] A. Schäfer, C. Huber, R. Ahlrichs, J. Chem. Phys. 1994, 100, 5829.

[5] A cage geometry with icosahedral symmetry shows distortions due to a first-order Jahn - Teller effect.

[6] R. B. Murphy, R. P. Messmer, Chem. Phys. Lett. 1991, 183, 443.

[7] S. Grimme, M. Waletzke, Phys. Chem. Chem. Phys. 2000, 2, 2075.

[8] T. Torelli, L. Mitas, Phys. Rev. Lett. 2000, 85, 1702.

[9] To allow comparison with experimental data, the zero-point energies must be considered also. These data have been calculated for the cage and bowl at the harmonic DFT/BP86 level. A contribution of only $0.13 \mathrm{eV}$ in favour of the bowl has been found, which is signifcantly smaller than our uncertainties for the relative electronic energies.

[10] TURBOMOLE Version 5.3, R. Ahlrichs, M. Bär, H.-P. Baron, R. Bauernschmitt, S. Böcker, M. Ehrig, K. Eichkorn, S. Elliott, F. Furche, F. Haase, M. Häser, H. Horn, C. Huber, U. Huniar, M. Kattannek, C. Kölmel, M. Kollwitz, K. May, C. Ochsenfeld, H. Öhm, A. Schäfer, U. Schneider, O. Treutler, M. von Arnim, F. Weigend, P. Weis, H. Weiss, Universität Karlsruhe, 2000.

[11] F. Weigend, M. Häser, Theor. Chem. Acc. 1997, 97, 331.

[12] T. H. Dunning, J. Chem. Phys. 1989, 90, 1007.

[13] Optimised RIMP2 auxiliary basis sets available via anonymous ftp from ftp.chemie.uni-karlsruhe.de/pub/cbasen.

[14] RIMR Version 2.2: A general multireference MP2 program. S. Grimme, M. Waletzke, Universität Münster, 2001.

Received: August 20, 2001 [Z286]

\section{Surface Structure of Untreated Parallel and Fishbone Carbon Nanofibres: An Infrared Study}

\author{
Tijmen George Ros, Adrianus Jacobus van Dillen, \\ John Wilhelm Geus, and \\ Diederik Christiaan Koningsberger*[a]
}

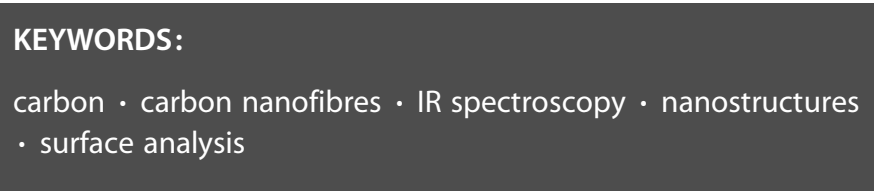

Carbon nanofibres (CNFs) that are obtained by catalytic decomposition of carbon-containing gases over small metal particles are a promising catalyst support material for liquid-phase reactions. The fibres are mechanically strong and can withstand the forces executed on them by stirring the reaction medium. Furthermore, the skeins of fibres possess a mesoporous macrostructure, decreasing the chance of encountering diffusion limitation during catalytic reactions in the liquid phase. The structure of the CNFs can be tuned by changing the growth conditions and their hydrophobicity can be altered by surface oxidation. Moreover, carbon nanofibres are very pure. No other types of carbon, such as carbon onions, fullerenes or amorphous carbon, are formed and no heteroatoms such as sulfur are incorporated during synthesis. They are chemically inert and can be used in strongly acidic or basic environments. Finally, when grown in a fluidised bed reactor, carbon nanofibres can be obtained at low cost, making an application as catalyst support material possible. ${ }^{[1]}$ After deactivation, CNFs can be readily combusted to recover the precious noble metal component of spent catalysts.

The mechanism of growth of CNFs has been studied extensively. ${ }^{[1-10]}$ By changing the growth conditions or the metal, carbon nanofibres of different structures can be obtained. Fishbone as well as parallel types of CNFs can be distinguished. With fishbone nanofibres the graphitic planes are oriented at an angle to the fibre axis, whereas with fibres of the parallel type the graphitic layers are oriented parallel to the axis. ${ }^{[3]}$ Due to the different structures, the surface structure of parallel and fishbone carbon nanofibres also have to differ. For parallel fibres, the surface consists of basal graphitic planes, whereas for fishbone fibres the edges of the graphitic layers are exposed. Consequently, one can assume that with parallel CNFs no hydrogen is present on the surface as it consists of closed graphene layers. With fishbone fibres, on the other hand, the graphitic edges could very well be terminated by hydrogen.

[a] Prof. D. C. Koningsberger, Dr. T. G. Ros, Dr. A. J. van Dillen, Prof. J. W. Geus Department of Inorganic Chemistry and Catalysis

Debye Institute, Utrecht University

P.O. Box 80083

3508 TB Utrecht (The Netherlands)

Fax: $(+30) 2511027$

E-mail:D.C.Koningsberger@chem.uu.nl 
For the use of carbon nanofibres as a catalyst support, it is important to be able to modify their surface by, for instance, the introduction of oxygen-containing surface groups. A better interaction of the fibres with catalyst precursor complexes can thus be achieved. It is also viable to use these surface oxides as anchoring sites for the immobilisation of larger molecules and metal-ligand systems. Finally, the hydrophobic or hydrophilic character of the carbon nanofibres can be controlled by surface modification. The difference in surface structure of parallel and fishbone carbon nanofibres may induce a different surface reactivity. For instance, one can expect that fishbone fibres, which terminate with the more reactive graphitic edges, are more susceptible to surface oxidation than parallel CNFs. As a first step towards an understanding of the surface reactivity and the mechanism of surface modification of carbon nanofibres, it is therefore important to gain knowledge about the surface structure of the fibres.

Teunissen and co-workers ${ }^{[6]}$ performed electron energy loss spectroscopy (EELS) measurements and concluded that for parallel carbon nanofibres no hydrogen was present at the edges of the fibres, which indicates that the outer layers consist of closed graphene planes. With fishbone CNFs, on the other hand, the edges of the fibres were terminated with carbonhydrogen bonds. These bonds were thought to belong to aliphatic $\mathrm{CH}_{2}$ groups, while no conclusions could be drawn concerning the presence or absence of aromatic $\mathrm{C}-\mathrm{H}$ groups. These findings correlate well with the assumed surface structure of the different fibres. Although this EELS study gave very valuable information about the surface structure of carbon nanofibres, the study did not take into account the possible connection between the presence of defects and carbon-hydrogen bonds. Accordingly, their EELS measurements were performed on small, perfectly ordered regions of parallel fibres. The volume of carbon nanofibres analysed was, furthermore, very small.

The presence of defects is very likely, since the graphitic ordering within carbon nanofibres is less than in well crystallised graphite. ${ }^{[1,10]}$ The $d(002)$ spacing of the CNFs, being larger than that of graphite, reflects this lower ordering. Synthetic graphite can be made by decomposition of gaseous hydrocarbons onto hot surfaces. Anderson ${ }^{[11]}$ found that in the early stages of graphitisation the interlayer spacing is higher than the ideal $0.336 \mathrm{~nm}$. Boehm ${ }^{[12]}$ also noted that the distance between the graphitic layers in microcrystalline carbon is larger than in graphite. The decreased graphitic ordering of CNFs is most probably the origin of defects in their structure. Hydrogen may well be localised at these defect sites. It is, therefore, possible that parallel carbon nanofibres also contain carbon-hydrogen bonds.

In this investigation, we have studied the surface structure of parallel and fishbone carbon nanofibres with infrared spectroscopy. With IR spectroscopy, a larger part of the surface of CNFs is analysed than with EELS. Therefore, it is possible to get an "overall" impression of the surface structure of carbon nanofibres. Although the strong absorption of light by carbon nanofibres makes infrared spectroscopic analysis very difficult, this study shows that IR spectroscopy is a suitable technique to investigate carbon nanofibres. A comparison of spectra of graphite and CNFs shows that the carbon nanofibres have a defect-rich structure and that carbon-hydrogen bonds are present on parallel as well as fishbone fibres.

Results

Figure 1 shows high resolution transmission electron microscopy (HRTEM) images of a parallel and a fishbone nanofibre. The graphitic layers are clearly visible. The parallel fibres (Figure $1 \mathrm{~A}$ ) have perfect graphitic regions alternated with defect regions.

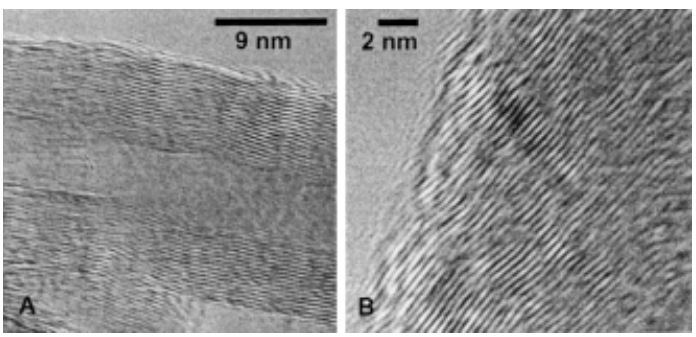

Figure 1. HRTEM micrographs of A) parallel and B) fishbone carbon nanofibres.

Other images demonstrate that regions exist where the planes are bent, broken or interrupted. The micrograph of the fishbone fibre (Figure 1B) shows that the graphitic layers are oriented at an angle to the outer surface of the fibre (namely, the axis of the fibre). Many planes are bent and careful examination establishes that planes merge, split and end. Moreover, the angle of the planes with respect to the fibre axis varies from almost parallel to more than $45^{\circ}$. From an image of fishbone fibres at lower magnification (see Figure 2), it can be seen that the fibres themselves are also bent.

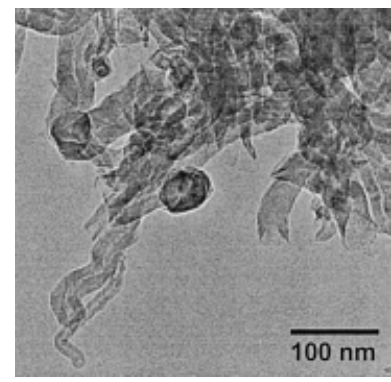

Figure 2. TEM micrograph of fishbone carbon nanofibres.

The growth of parallel carbon nanofibres from $\mathrm{CO} / \mathrm{H}_{2}$ at $600{ }^{\circ} \mathrm{C}$ results in a relatively open macroscopic structure of a low mechanical strength and density. ${ }^{[3,4]}$ The aggregates appear powdery and can easily be broken. The results of the analysis of the nitrogen physisorption data and the observed fibre diametres with TEM are presented in Table 1. A specific surface area of $158 \mathrm{~m}^{2} \mathrm{~g}^{-1}$ and a pore volume of $1.16 \mathrm{~mL} \mathrm{~g}^{-1}$ are obtained. No micropores are present. The diametre of the fibres varies between 15 and $20 \mathrm{~nm}$. The fishbone carbon nanofibres, grown from $\mathrm{CH}_{4}$ at $570{ }^{\circ} \mathrm{C}$, exhibit a strongly interwoven structure. This 
Table 1. $\mathrm{N}_{2}$-physisorption data and diameters of parallel and fishbone carbon nanofibres.

\begin{tabular}{|lllll|} 
& $\begin{array}{l}\text { BET surface area } \\
{\left[\mathrm{m}^{2} \mathrm{~g}^{-1}\right]}\end{array}$ & $\begin{array}{l}\text { pore volume } \\
{\left[\mathrm{mL} \mathrm{g}^{-1}\right]}\end{array}$ & $\begin{array}{l}\text { micropore volume } \\
{\left[\mathrm{mLg}^{-1}\right]}\end{array}$ & $\begin{array}{l}\text { diameter } \\
{[\mathrm{nm}]}\end{array}$ \\
\hline parallel & 158 & 1.16 & 0.00 & $15-20$ \\
fishbone & 103 & 0.31 & 0.00 & $20-90$
\end{tabular}

results in mechanically strong macroscopic bodies of a higher density than that of parallel nanofibres. A specific surface area of $103 \mathrm{~m}^{2} \mathrm{~g}^{-1}$ and a pore volume of $0.31 \mathrm{~mL} \mathrm{~g}^{-1}$ are found, again with no micropores present (see Table 1). The diametre of the fishbone fibres ranges from 20 to $90 \mathrm{~nm}$. For both types of fibre, a $d(002)$ spacing of $0.344 \mathrm{~nm}$ is found with X-ray diffraction (XRD). The width of the XRD peak is large compared to that of graphite.

It must be noted that $\mathrm{Al}_{2} \mathrm{O}_{3}$, originating from the growth catalyst, is still present in the nanofibre samples. We ascertained that the presence of $\mathrm{Al}_{2} \mathrm{O}_{3}$ did not interfere with the infrared study of the CNFs. The $\mathrm{Al}_{2} \mathrm{O}_{3}$ was not removed, since the prolonged treatment with concentrated acids, needed for removal of the $\mathrm{Al}_{2} \mathrm{O}_{3}$, would also modify the surface of the nanofibres.

In Figure 3, diffuse reflectance Fourier-transform (DRIFT) infrared spectra of parallel CNFs and a Darco KBB activated carbon are displayed. Whereas the activated carbon exhibits clearly distinguishable infrared bands, the spectrum of the parallel

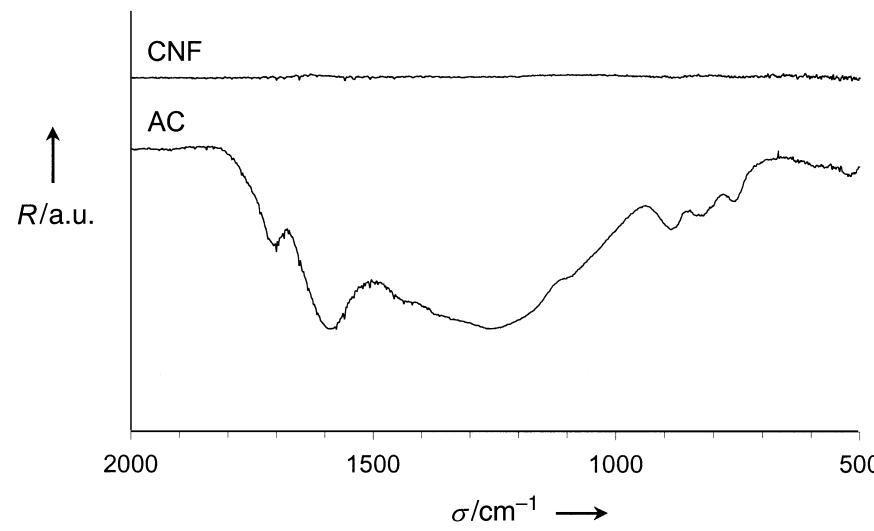

Figure 3. DRIFT spectra of parallel carbon nanofibres (CNF) and a DARCO KBB activated carbon (AC).

fibres shows only one straight line. These findings illustrate that although DRIFT spectroscopy is a surface-sensitive technique, it is not suitable for obtaining spectra of carbon nanofibres. The difference between the CNFs and the activated carbon is remarkable. It is clear that the former absorbs much more infrared light than the latter; in other words, carbon nanofibres are highly opaque.

In order to get better infrared spectra of carbon nanofibres, transmission IR was used. The strong IR absorbance of the fibres necessitated a very low sample concentration. To allow comparison, transmission levels of all spectra were kept approximately the same. It was established that, within the transmission window used, the intensity of the bands did not depend upon the transmission level of the spectra. Figure 4 shows spectra of parallel and fishbone nanofibres in the $2000-500 \mathrm{~cm}^{-1}$ region.

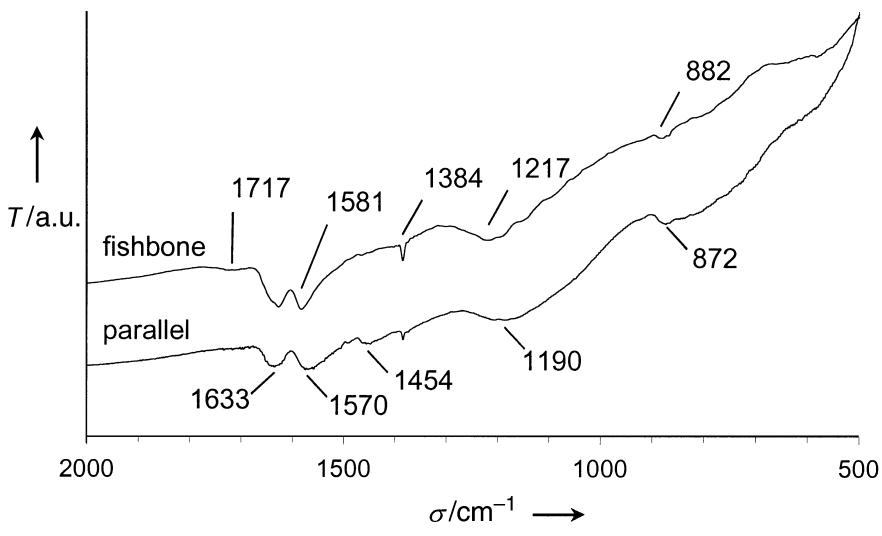

Figure 4. IR spectra of untreated parallel and fishbone carbon nanofibres.

Table 2 summarises all infrared band assignments. As significant water contamination due to the low sample concentrations was likely, the band at $1633 \mathrm{~cm}^{-1}$ can be discounted as being due to adsorbed water. ${ }^{[13,14]}$ This is supported by the observation that the band disappeared when the $\mathrm{KBr}$ - fibre mixture was dried at $80^{\circ} \mathrm{C}$ for several days before the tablet was pressed. The water is most probably exclusively adsorbed onto the $\mathrm{KBr}$ as the fibres are hydrophobic and no $\mathrm{H}_{2} \mathrm{O}$ evolved during thermogravimetric analysis (TGA) with a fibre sample. The sharp peak at $1384 \mathrm{~cm}^{-1}$ can also be discounted as being due to traces of nitrate, formed from $\mathrm{NO}_{x}$ taken up from the air. ${ }^{[15,16]}$ Both the 1384 and the $1633 \mathrm{~cm}^{-1}$ bands are also present in the $\mathrm{KBr}$ backgrounds.

\begin{tabular}{|lll|}
\hline $\begin{array}{l}\text { Table 2. Infrared absorption assignments of found for carbon nanofibres and } \\
\text { graphite. }\end{array}$ \\
$\begin{array}{lll}\text { Wavenumber } \\
{\left[\mathrm{cm}^{-1}\right]}\end{array}$ & Assignment & Reference \\
\hline 3012 & aromatic $\mathrm{C}-\mathrm{H}$ stretch & {$[17]$} \\
2947 & $\mathrm{CH}_{2} / \mathrm{CH}_{3}$ stretch & {$[17]$} \\
2917 & $\mathrm{CH}_{2} / \mathrm{CH}_{3}$ stretch & {$[17]$} \\
2846 & $\mathrm{CH}_{2} / \mathrm{CH}_{3}$ stretch & {$[17]$} \\
$1717-1712$ & $\mathrm{C}=\mathrm{O}_{\text {stretch }}$ & {$[13,17,19,20]$} \\
1633 & adsorbed water & {$[13,14]$} \\
$1580-1570$ & aromatic ring stretch & {$[13,17,18]$} \\
1454 & $\mathrm{CH}_{2} / \mathrm{CH}_{3}$ bend & {$[17,23]$} \\
1384 & nitrate & {$[15,16]$} \\
$1217-1188$ & $\mathrm{C}-\mathrm{C}_{\text {stretch }}$ & {$[13,17]$} \\
$880-870$ & isolated aromatic $\mathrm{C}-\mathrm{H}$ out-of-plane bend & {$[17]$} \\
\hline
\end{tabular}

The bands at about 1580 and $1200 \mathrm{~cm}^{-1}$ can be assigned to carbon skeleton vibrations. ${ }^{[13,14,17,18]}$ The higher wavenumber absorption is associated with an aromatic ring stretching mode, found at slightly higher wavenumbers in carbon blacks by Prest et al. ${ }^{[13]}\left(1595 \mathrm{~cm}^{-1}\right)$ and in coal samples by Painter et al. ${ }^{[17]}$ $\left(1600 \mathrm{~cm}^{-1}\right)$. For parallel carbon nanofibres, however, Shaffer et al. ${ }^{[14]}$ observed this band at $1550 \mathrm{~cm}^{-1}$ while Mawhinney and co-authors ${ }^{[18]}$ detected this band at $1581 \mathrm{~cm}^{-1}$ for single-walled 
carbon nanotubes. The lower wavenumber absorption at about $1200 \mathrm{~cm}^{-1}$ is related to $C-C$ stretching vibrations. ${ }^{[13]}$ Prest $^{[13]}$ and Shaffer ${ }^{[14]}$ observed this band at 1245 and about $1200 \mathrm{~cm}^{-1}$, respectively.

The band at $880-870 \mathrm{~cm}^{-1}$, present in both types of fibre, can be assigned to isolated aromatic $\mathrm{C}-\mathrm{H}$ out-of-plane bending vibrations. ${ }^{[17]}$ Painter et al. found that after deconvolution two bands at 888 and $864 \mathrm{~cm}^{-1}$ resulted that could be ascribed to lone aromatic $\mathrm{C}-\mathrm{H}$ groups in different local environments. The very weak band at $1717 \mathrm{~cm}^{-1}$, present in the spectrum of the fishbone nanofibres, is attributed to the $\mathrm{C}=\mathrm{O}$ stretching vibration of carbonyl or carboxylic acid groups. ${ }^{[13,17,19,20]}$ TGAMS (TGA - mass spectrometric) analysis showed that a small mass loss is accompanied with the evolution of $\mathrm{CO}$ with the parallel nanofibres and the release of $\mathrm{CO}$ and $\mathrm{CO}_{2}$ with the fishbone CNFs. Apparently, some oxygen is already present on untreated nanofibres. Considering the finding that only fishbone CNFs lose $\mathrm{CO}_{2}$ when heated in $\mathrm{Ar}$, the $1717 \mathrm{~cm}^{-1}$ band may be associated with the $\mathrm{C}=\mathrm{O}$ vibration of carboxyl groups. ${ }^{[12,21,22]}$ Finally, the additional band at $1454 \mathrm{~cm}^{-1}$ in the spectrum of the parallel fibres is assigned to $\mathrm{CH}_{2}$ and $\mathrm{CH}_{3}$ bending vibrations. ${ }^{[17,23]}$ Painter et al. ${ }^{[17]}$ and Gómez-Serrano and co-workers ${ }^{[23]}$ observed this vibration at 1450 and $1460 \mathrm{~cm}^{-1}$, respectively.

The $3200-2700 \mathrm{~cm}^{-1}$ region of the spectra provides more insight into the presence of carbon-hydrogen groups on the fibres (see Figure 5). Four minima can be distinguished at 3012, 2947, 2917 and $2846 \mathrm{~cm}^{-1}$. The peak at $3012 \mathrm{~cm}^{-1}$ can be assigned to aromatic $\mathrm{C}-\mathrm{H}$ stretching vibrations, whereas the other three absorptions are associated with $\mathrm{CH}_{2}$ and $\mathrm{CH}_{3}$ stretching vibrations. Painter and co-workers ${ }^{[17]}$ observed these bands at about 2950, 2920 and $2850 \mathrm{~cm}^{-1}$. On the basis of the assignments most often made in this region of the spectrum, it is tempting to attribute the peak at $2947 \mathrm{~cm}^{-1}$ to antisymmetric stretching modes of $\mathrm{CH}_{3}$ groups and the minima at 2917 and $2846 \mathrm{~cm}^{-1}$ to the antisymmetric and symmetric vibrations of $\mathrm{CH}_{2}$ groups. Unfortunately, with carbonaceous materials these bands must be considered a composite of various overlapping contributions. ${ }^{[17]}$ Infrared studies of hydroaromatic model compounds have shown that the position of the vibrational bands of both methyl and methylene groups is dependent upon the structure of those compounds. Only the absorption at about

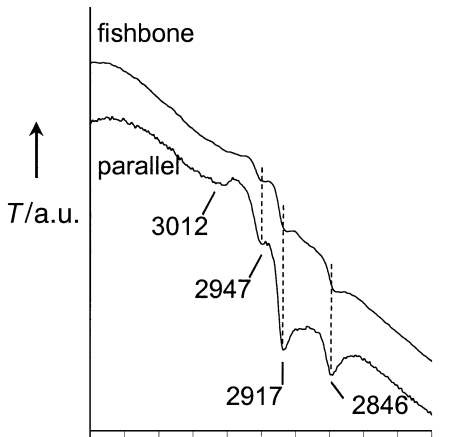

320031003000290028002700

$\sigma / \mathrm{cm}^{-1} \longrightarrow$

Figure 5. IR spectra of untreated parallel and fishbone carbon nanofibres.

$2850 \mathrm{~cm}^{-1}$ is not very sensitive to the structure and thus can point to the presence of $\mathrm{CH}_{2}$ groups. In summary, the three modes between 3000 and $2800 \mathrm{~cm}^{-1}$ give information about the $\mathrm{CH}_{2} / \mathrm{CH}_{3}$ content in carbonaceous materials, but a distinction between $\mathrm{CH}_{2}$ and $\mathrm{CH}_{3}$ groups cannot easily be made.

In order to obtain further information about which bands can be associated with defects, spectra were recorded of a low $\left(<10 \mathrm{~m}^{2} \mathrm{~g}^{-1}\right.$, Fluka) and a high $\left(300 \mathrm{~m}^{2} \mathrm{~g}^{-1}\right.$, "HSAG300", TIMCAL) surface area graphite. Figure $6 \mathrm{~A}$ represents the $2000-800 \mathrm{~cm}^{-1}$ region of both graphites. The Fluka graphite only shows a weak band at $1578 \mathrm{~cm}^{-1}$, attributed to aromatic ring vibration. The HSAG300 graphite, in contrast, shows four additional absorptions at 1712, 1455, 1188 and $895 \mathrm{~cm}^{-1}$. Furthermore, the intensity of the $1578 \mathrm{~cm}^{-1}$ band is enhanced considerably. Figure $6 \mathrm{~B}$ shows the $3100-2700 \mathrm{~cm}^{-1}$ region of the spectra of both graphites. It is clear that the Fluka graphite does not possess any $\mathrm{CH}_{2} / \mathrm{CH}_{3}$ groups, whereas the carbon-hydrogen stretching vibrations are clearly visible in the spectrum of the HSAG300 graphite. A weak band at $3008 \mathrm{~cm}^{-1}$ can also be distinguished.

\section{Discussion}

The electron microscopy and XRD data indicate that defects are present in the graphitic structure of the carbon nanofibres. With
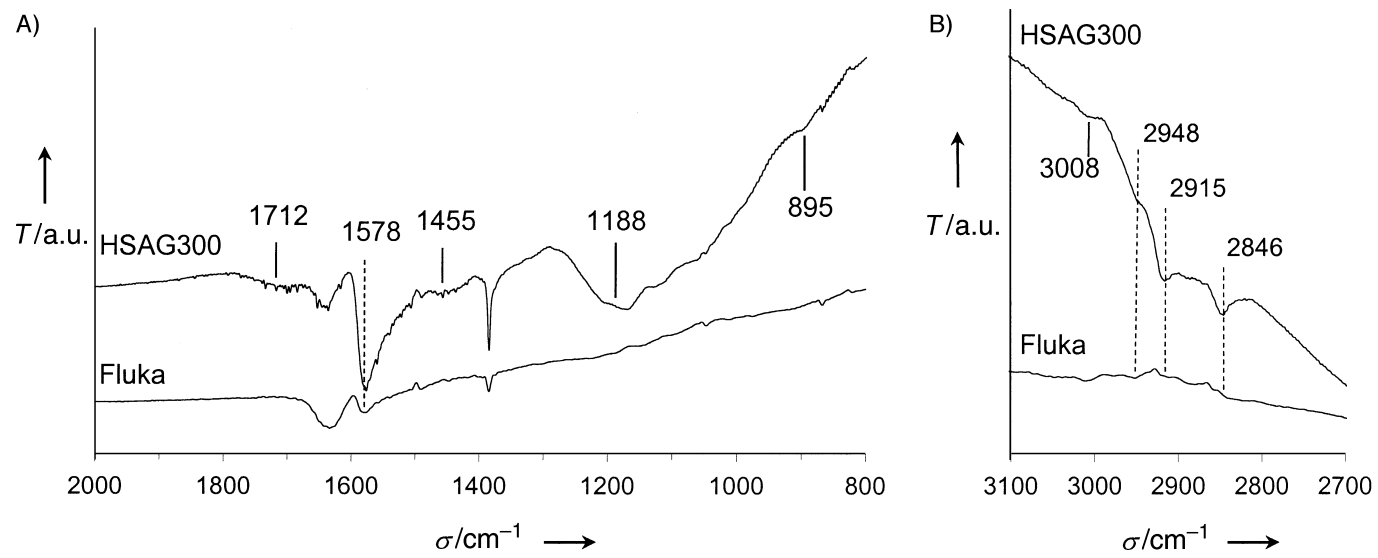

Figure 6. A) IR spectra of graphite with a low (Fluka) and a high (HSAG300) surface area. B) Focus on the C-H stretch region. 
HRTEM the defects can be imaged. The bending of the fibres themselves has to result from defects in the graphitic structure. The $d(002)$ value of $0.344 \mathrm{~nm}$ found with XRD is significantly larger than the $d(002)$ spacing of graphite of $0.336 n m . .^{[24]}$ Together with the relatively large width of the $d(002)$ peak, this implies less graphitic ordering than in graphite and thus a defect-rich structure.

The infrared data show that aromatic $\mathrm{C}-\mathrm{H}$ as well as $\mathrm{CH}_{2} / \mathrm{CH}_{3}$ groups are present on the CNFs. These groups must be localised at defect sites and, for the fishbone fibres, at the edges of the planes. The presence of the $1200 \mathrm{~cm}^{-1} \mathrm{C}-\mathrm{C}$ stretching vibration also points to the existence of defects. Both the 1580 and the $1200 \mathrm{~cm}^{-1}$ bands are present in the spectrum of a heat-treated carbon black. ${ }^{[13]}$ However, single-walled carbon nanotubes, heated to $800^{\circ} \mathrm{C}$ in vacuum, show only the vibration at $1580 \mathrm{~cm}^{-1}$. ${ }^{[18]}$ The band at $1200 \mathrm{~cm}^{-1}$, therefore, has to be associated with defects in carbonaceous materials. ${ }^{[14]}$

For the comparison between the low and high surface area graphites, we assume for the case of the high surface area HSAG300 graphite that the graphitic domains are small and that defects are present in the structure, in contrast to the Fluka graphite. This assumption is supported by the larger width of the XRD $d(002)$ peak measured for the HSAG300 graphite. The Fluka graphite, which supposedly has perfectly ordered graphitic domains, shows only a weak aromatic ring vibration at $1578 \mathrm{~cm}^{-1}$. In contrast to the Fluka graphite, the HSAG300 sample shows a clear, broad absorption at $1188 \mathrm{~cm}^{-1}$. These results clearly indicate that the absorption at $1200 \mathrm{~cm}^{-1}$ in graphitic materials is related to the presence of defects in the structure. Along with the defects in the structure, other bands also appear in the infrared spectrum. Firstly, the peaks at 1455 , 2846, 2915 and $2948 \mathrm{~cm}^{-1}$ show that $\mathrm{CH}_{2} / \mathrm{CH}_{3}$ groups are present. The absorptions at 895 and $3008 \mathrm{~cm}^{-1}$ point out that the presence of defects leads to aromatic $\mathrm{C}-\mathrm{H}$ groups and the $1712 \mathrm{~cm}^{-1}$ band indicates the appearance of some oxygen containing surface groups. Finally, the decrease of the size of the graphitic domains results in an increase of the intensity of the $1578 \mathrm{~cm}^{-1}$ absorption, because symmetry restrictions are relieved for more aromatic rings.

The infrared results obtained with the two graphites enable us to interpret the spectra of the parallel and the fishbone carbon nanofibres in more detail. We conclude that the graphitic structure of both types of fibres is rich in defects because their spectra show the $\mathrm{C}-\mathrm{C}$ stretching vibration at $1200 \mathrm{~cm}^{-1}$. These defects give rise to the presence of $\mathrm{CH}_{2} / \mathrm{CH}_{3}$ groups as well as aromatic $\mathrm{C}-\mathrm{H}$ groups on both types of fibres. Moreover, on the fishbone CNFs some surface oxides were formed at the defect sites. For the parallel fibres, the presence of aromatic $\mathrm{C}-\mathrm{H}$ groups is clearly shown by bands at 872 and $3012 \mathrm{~cm}^{-1}$. The fishbone fibres, on the other hand, show only a band at $882 \mathrm{~cm}^{-1}$. The difference in position of the isolated aromatic $\mathrm{C}-\mathrm{H}$ out-of-plane bending vibration at $882 \mathrm{~cm}^{-1}$ for the fishbone CNFs and at $872 \mathrm{~cm}^{-1}$ for the parallel fibres points to differences in local environment. ${ }^{[17]}$ For the presence of $\mathrm{CH}_{2} / \mathrm{CH}_{3}$ groups, the same trend is visible. $\mathrm{CH}_{2} / \mathrm{CH}_{3}$ groups are clearly present on the parallel CNFs (minima at 1454, 2846, 2917 and $2947 \mathrm{~cm}^{-1}$ ), whereas for the fishbone fibres only weak absorptions in the $3000-2800 \mathrm{~cm}^{-1}$ region can be distinguished.

Since with parallel fibres the $\mathrm{CH}_{2} / \mathrm{CH}_{3}$ bands are more intense in the $3000-2800 \mathrm{~cm}^{-1}$ region and a peak at $1454 \mathrm{~cm}^{-1}$ is visible, it seems that the concentration of these groups is higher with the parallel than with the fishbone fibres. However, other factors may also influence the intensity of these bands. Because of the very high absorption of the CNFs, it is likely that the penetration depth of the IR radiation is smaller than the diametre of the fibres. Therefore, most of the radiation is blocked by the nanofibres: Light only passes through at the edges of the fibres. This explains the very low sample concentrations needed to obtain a signal. Consequently, the diametre of the fibres and thus their external surface area influences the intensity of the IR signal. The external surface area of parallel fibres is higher than that of fishbone CNFs and as a result more intense $\mathrm{CH}_{2} / \mathrm{CH}_{3}$ bands are detected. This explanation is supported by the finding that parallel fibres with an external surface area of $300 \mathrm{~m}^{2} \mathrm{~g}^{-1}$ (grown out of supported iron particles) exhibited even more intense $\mathrm{CH}_{2} / \mathrm{CH}_{3}$ bands. Another factor that can play a role is the macroscopic density of the carbon nanofibre particles. Particles of parallel fibres are much less dense than those of fishbone CNFs. Therefore, more infrared light can pass through a particle of parallel carbon nanofibres.

The higher intensity of the $\mathrm{CH}_{2} / \mathrm{CH}_{3}$ bands in parallel carbon nanofibres cannot be unambiguously associated with a higher concentration of those groups. We therefore conclude that, overall, there is not much difference between parallel and fishbone carbon nanofibres.

At first sight, the present results obtained with infrared and the findings of Teunissen et al. with EELS ${ }^{[6]}$ seem partly contradictory. Teunissen found that with the parallel carbon nanofibres no carbon-hydrogen bonds could be detected. For the fishbone CNFs, aliphatic $\mathrm{CH}_{2}$ groups were detected and no conclusion could be drawn concerning the presence or absence of aromatic $\mathrm{C}-\mathrm{H}$ groups. However, the EELS results were obtained by analysing a perfectly ordered region of a parallel CNF. The findings described above have made clear that the presence of $\mathrm{CH}_{2} / \mathrm{CH}_{3}$ groups is related to defects in the graphitic structure. In view of this, both observations are complementary. The infrared results obtained with fishbone nanofibres have led to the conclusion that these fibres contain $\mathrm{CH}_{2} / \mathrm{CH}_{3}$ groups. Unfortunately, no distinction between these groups can be made. These findings are in accordance with the conclusions drawn by Teunissen. The presence of aromatic $\mathrm{C}-\mathrm{H}$ was not observed by EELS, but IR has been able to detect these groups on both types of fibres. Considering the structure of the fishbone $\mathrm{CNFs}$, it is very likely that the carbon edges end in $\mathrm{CH}_{2} / \mathrm{CH}_{3}$ or aromatic $\mathrm{C}-\mathrm{H}$ groups.

Because of the defect-rich graphitic structure of both parallel and fishbone carbon nanofibres, there does not seem to be much difference in their surface composition. It is, therefore, also possible that the surface reactivity of parallel and fishbone fibres does not differ significantly. The surface reactivity of carbon nanofibres towards oxidising agents will be dealt with in a separate paper. It should be noted that from a practical point of view, fishbone CNFs are more favourable as a catalyst support 
than parallel fibres. Fishbone fibres have a higher cluster density and are mechanically stronger. Furthermore, they can be grown in higher yields.

\section{Experimental Section}

Fibre growth:

Parallel and fishbone type carbon nanofibres were produced by catalytic decomposition of $\mathrm{CO} / \mathrm{H}_{2}$ or $\mathrm{CH}_{4}$ on $\mathrm{Ni} / \mathrm{Al}_{2} \mathrm{O}_{3}$ catalysts, respectively. ${ }^{[3-6]}$

The $\mathrm{Ni} / \mathrm{Al}_{2} \mathrm{O}_{3}$ catalysts with 20 or $30 \mathrm{wt} \% \mathrm{Ni}$ metal loading were synthesised by the deposition-precipitation technique. ${ }^{[25]}$ Alumina (Alon-C, Degussa) was suspended in an acidified aqueous solution of nickel nitrate (Acros, 99\%) and diluted ammonia was injected within two hours at room temperature during vigorous stirring until the $\mathrm{pH}$ had reached a value of 8.5. After overnight stirring, the suspension was filtered, washed and dried at $120^{\circ} \mathrm{C}$. Finally, the catalyst was calcined at $600^{\circ} \mathrm{C}$ in still air for $3 \mathrm{~h}$.

Parallel carbon nanofibres were synthesised in small quantities in a fully automated microflow system. Fishbone carbon nanofibres, on the other hand, were grown on a larger scale in a manually operated set-up. Therefore, somewhat different synthesis conditions were employed.

For parallel carbon nanofibres, the $20 \mathrm{wt} \% \mathrm{Ni} / \mathrm{Al}_{2} \mathrm{O}_{3}$ catalyst $(100 \mathrm{mg}$ ) was reduced at $700^{\circ} \mathrm{C}$ in $20 \% \mathrm{H}_{2} / \mathrm{Ar}$ (flow rate $6 \mathrm{Lh}^{-1}$ ) in a microflow reactor for $2 \mathrm{~h}$. After reduction, the temperature was decreased to $600^{\circ} \mathrm{C}$ and synthesis gas $\left(20 \% \mathrm{CO}\right.$ and $7 \% \mathrm{H}_{2}$ in $\mathrm{Ar}$, flow rate $\left.6 \mathrm{Lh}^{-1}\right)$ was passed through the reactor over a $10 \mathrm{~h}$ period. After treatment, about $0.5 \mathrm{~g}$ of parallel CNFs were collected.

For fishbone $\mathrm{CNFs}$, the $30 \mathrm{wt} \% \mathrm{Ni} / \mathrm{Al}_{2} \mathrm{O}_{3}$ catalyst $(0.5 \mathrm{~g})$ was reduced at $600{ }^{\circ} \mathrm{C}$ in $14 \% \mathrm{H}_{2} / \mathrm{N}_{2}$ (flow rate $21 \mathrm{Lh}^{-1}$ ) in a vertical tubular reactor (diametre $3 \mathrm{~cm}$ ) for $2 \mathrm{~h}$. After decreasing the temperature to $570^{\circ} \mathrm{C}$, methane $\left(50 \%\right.$ in $\mathrm{N}_{2}$, flow rate $27 \mathrm{Lh}^{-1}$ ) was passed through the catalyst bed for $6.5 \mathrm{~h}$. The yield of fibres amounted to approximately $12 \mathrm{~g}$.

TEM samples were prepared by dispersing ground nanofibres in ethanol by ultrasound and drying a drop on a copper grid covered by a holey carbon film. They were imaged in a Philips CM-200 electron microscope operating at $200 \mathrm{kV}$.

CNF samples were degassed at $120^{\circ} \mathrm{C}$ under vacuum for at least $16 \mathrm{~h}$ and nitrogen adsorption-desorption isotherms were measured at $77 \mathrm{~K}$ on a Micromeretics ASAP 2400 apparatus. Specific surface areas and pore volumes were calculated from the data obtained.

Powder XRD measurements were performed using an ENRAFNONIUS XRD system equipped with a curved position-sensitive INEL detector operating up to a width of $120^{\circ}(2 \theta)$. The applied radiation was $\mathrm{Co}_{\mathrm{K} \alpha}(\lambda=1.78897 \AA)$.

TGA analyses were carried out on a Netzsch STA-429 thermobalance. The gasses evolved during analysis were monitored by a Fisons Thermolab quadropole mass spectrometer, using a capillary situated directly above the sample cup. Samples of $20-100 \mathrm{mg}$ were heated in $3.6 \mathrm{Lh}^{-1} \mathrm{Ar}$ at a rate of $300^{\circ} \mathrm{Ch}^{-1}$ to $850^{\circ} \mathrm{C}$.

DRIFT was executed on a Perkin - Elmer 1600 spectrometre equipped with a Spectra-Tech DRIFT accessory. 256 scans were taken at a resolution of $2 \mathrm{~cm}^{-1}$ and a strong apodisation. Dilutions of $1 \%(\mathrm{w} / \mathrm{w})$ powdered sample in $\mathrm{KBr}$ were used. Transmission infrared spectra were recorded on a Perkin - Elmer 2000 spectrometre equipped with an air dryer to exclude water vapour and carbon dioxide. 100 scans were taken at a resolution of $8 \mathrm{~cm}^{-1}$ and a boxcar apodisation. Samples were prepared by thoroughly mixing a small amount of ground nanofibres with predried $\mathrm{KBr}$. Tablets were pressed at $4 \times$ $10^{3} \mathrm{~kg} \mathrm{~cm}^{-1}$ in vacuum for $2 \mathrm{~min}$. The concentrations of the nanofibres ranged from 0.1 to $1 \%(\mathrm{w} / \mathrm{w})$. All transmission spectra were baseline corrected.

The authors wish to acknowledge Prof. Dr. J. H. van der Maas of the Department of Vibrational Spectroscopy, Utrecht University, for the discussions about the IR data. This work was supported by the Netherlands' Organisation for Scientific Research (NWO).

[1] K. P. de Jong, J. W. Geus, Catal. Rev. Sci. Eng. 2000, 42, $481-510$

[2] E. Boellaard, P. K. de Bokx, A. J. H. M. Kock, J. W. Geus, J. Catal. 1985, 96, $481-490$.

[3] M.S. Hoogenraad, PhD Thesis, Utrecht University (The Netherlands), 1995

[4] M. S. Hoogenraad, M. F. Onwezen, A. J. van Dillen, J. W. Geus, Stud. Surf. Sci. Catal. 1995, 101, $1331-1339$.

[5] J. W. Geus, M. S. Hoogenraad, A. J. van Dillen, Maert. Res. Soc. Symp. Proc. $1995,368,87-98$.

[6] W. Teunissen, PhD Thesis, Utrecht University (The Netherlands), 2000.

[7] "Carbon Fibers Filaments and Composites": R. T. K. Baker, NATO ASI Ser. Ser. C 1990, 177, $405-439$.

[8] "Carbon Fibers Filaments and Composites": J. L. Figueiredo, C. A Bernardo, NATO ASI Ser., Ser. C 1990, 177, 441 - 457.

[9] "Carbon Fibers Filaments and Composites": A. Sacco, NATO ASI Ser., Ser. C 1990, 177, 459- 505.

[10] N. M. Rodriguez, J. Mater. Res. 1993, 8, 3233 - 3250.

[11] J. R. Anderson, Structure of Metallic Catalysts, Academic Press, London, 1975, p. 81

[12] H. P. Boehm, Adv. Catal. 1966, 16, 179-274.

[13] "Colloids and Surfaces in Reprographic Technology": W. M. Prest, R. A. Mosher, ACS Symp. Ser. 1982, 200, 225-247.

[14] M. S. P. Shaffer, X. Fan, A. H. Windle, Carbon 1998, 36, $1603-1612$.

[15] K. Nakamoto, Infrared and Raman Spectra of Inorganic and Coordination Compounds, 4th ed., John Wiley and Sons, New York, NY, 1986, p. 124.

[16] U. Zielke, K. J. Hüttinger, W. P. Hoffman, Carbon 1996, 34, 983.

[17] P. Painter, M. Starsinic, M. Coleman in Fourier Transform Infrared Spectroscopy, Applications to Chemical Systems, Vol. 4 (Eds.: J. R. Ferraro, L. J. Basile), Academic Press, Orlando, FL, 1985, pp. 169- 241.

[18] D. B. Mawhinney, V. Naumenko, A. Kuznetsova, J. T. Yates, J. Am. Chem Soc. 2000, 122, $2383-2384$.

[19] J. Chen, M. A. Hamon, H. Hu, Y. Chen, A. M. Rao, P. C. Eklund, R. C. Haddon, Science 1998, 282, $95-98$.

[20] A. Kuznetsova, D. B. Mawhinney, V. Naumenko, J.T. Yates, J. Liu, R. E. Smalley, Chem. Phys. Lett. 2000, 321, $292-296$.

[21] H. P. Boehm, Carbon 1994, 32, 759- 769.

[22] J. L. Figueiredo, M. F. R. Pereira, M. M. A. Freitas, J. J. M. Órfão, Carbon $1999,37,1379-1389$.

[23] V. Gómez-Serrano, F. Piriz-Almeida, C. J. Durán-Valle, J. Pastor-Villegas, Carbon 1999, 37, 1517-1528.

[24] The Powder Diffraction File, release 1993, International Centre for Diffraction Data.

[25] J. W. Geus, Stud. Surf. Sci. Catal. 1983, 16, 1-33.

Received: July 17, 2001 [Z263] 